\title{
Recovery of iron from iron ore slimes by selective flocculation
}

\author{
by R. Kumar*, and N.R. Mandre*
}

\section{Synopsis}

The beneficiation of iron ore slimes by selective flocculation was studied. Polyacrylamide (PAM) and guar gum were used as flocculant, along with sodium hexametaphosphate (SHMP) as a dispersant. The samples collected were initially subjected for chemical and mineralogical studies. The mineralogical studies indicated the presence of haematite and goethite as the principal iron-bearing minerals, with quartz and kaolinite as gangue minerals. The selective flocculation tests showed that the Fe grade can be enhanced from $58.24 \%$ to $64.60 \% \mathrm{Fe}$ at a recovery of $66.33 \%$ using polyacrylamide as the flocculant. A Fe grade of $63.20 \%$ at a recovery of $68.04 \%$ was obtained using guar gum as flocculant. The efficacy of the studies was analysed using a separation index, which indicated that the higher separation index was obtained with the tests employing polyacrylamide as the flocculant.

\section{Keywords}

selective flocculation, iron ore slimes, polyacrylamide, guar gum, beneficiation. flotation, decreased gravitational effect in gravity separation, and reduced drag force in magnetic separation, among other factors (Batisteli and Peres, 2008; Das et al., 2007; Dworzanowski, 2012; Rocha, Caneado, and Peres, 2010). Therefore, it is in this regard that selective flocculation has gained importance in treating slimes in recent years.

In the earlier research work, selective flocculation studies of iron ore were carried out using dispersant in the grinding circuit with starch as a flocculant. The studies indicated that the dosing sequence of various reagents affects the effectiveness of selective flocculation (Ma, 2012). A typical study, carried out on alumina-rich Indian iron ore slimes, indicated that amylopectin, a constituent of starch, is selective towards flocculation of haematite particles (Ravishankar and Pradip Khosla, 1995). Many studies have been carried out on selective flocculation employing different flocculants (Drzymala and Fuerstenau, 1981;

Weissenborn, Warren, and Dunn, 1994; Jin, $\mathrm{Hu}$, and $\mathrm{Hou}, 1987$; Haselhuhn, Carlson, and Kawatra, 2012; Panda et al., 2013). However, the characteristics of ores/slimes from different localities differ substantially. Therefore, a study on selective flocculation of typical iron ore tailings employing polyacrylamide and guar gum as the flocculants was conducted. The study also included an analysis of the efficacy of the process by using a separation index technique.

\section{Materials and method}

A typical iron ore slimes sample was collected from a slime pond at Kiriburu iron ore processing plant, Jharkhand, India. Guar gum and polyacrylamide (non-ionic), obtained from Saiguru Food and Gum Industries, Mumbai

\footnotetext{
* Department of Fuel and Mineral Engineering, Indian School of Mines, Dhanbad, India.

(C) The Southern African Institute of Mining and Metallurgy, 2017. ISSN 2225-6253. Paper received Nov. 2015; revised paper received Nov. 2016.
} 


\section{Recovery of iron from iron ore slimes by selective flocculation}

and Merck, India respectively were used as flocculants. Other reagents, including sodium hexametaphosphate, sodium hydroxide, and hydrochloric acid, were of analytical grade.

\section{Chemical studies}

Chemical analysis was carried out by double-beam atomic absorption spectroscopy using Thermofisher apparatus. The results of the studies indicated that the sample contains $58.24 \% \mathrm{Fe}$, with $4.72 \% \mathrm{SiO}_{2}, 3.47 \% \mathrm{Al}_{2} \mathrm{O}_{3}$, and had $5.18 \%$ loss on ignition (LOI).

\section{QEMSCAN}

Mineralogical analysis was carried out using QEMSCAN (model 4300), and the results are given in Table I. The major minerals present in the sample were haematite, goethite, and limonite, with gibbsite, kaolinite, and quartz as the chief gangue minerals. About $97 \%$ (by mass) consisted of haematite, goethite, and limonite with the remaining $3 \%$ consisting of other minerals such as quartz, kaolinite, gibbsite, and magnetite.

The mineral composition of the sample is shown in Figure 1. It can be seen that most of the gangue minerals are associated with the haematite phase. The haematite content is higher in the smaller size fractions than the gangue minerals. This indicates the enrichment of iron minerals in the smaller size fractions.

\begin{tabular}{|c|c|c|c|}
\hline \multicolumn{4}{|c|}{ Mineralogical analysis of iron ore slime, mass $\%$} \\
\hline Minerals & Mass (\%) & 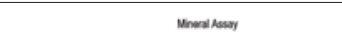 & \\
\hline Gibbsite & 0.20 & & \\
\hline Goethite & 28.12 & & \\
\hline Hematite & 61.30 & & $=-$ \\
\hline Magnetite & 0.01 & & $=$ \\
\hline Limonite & 8.42 & & 남 \\
\hline Kaolinite & 0.54 & 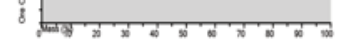 & \\
\hline Quartz & 1.42 & & \\
\hline
\end{tabular}

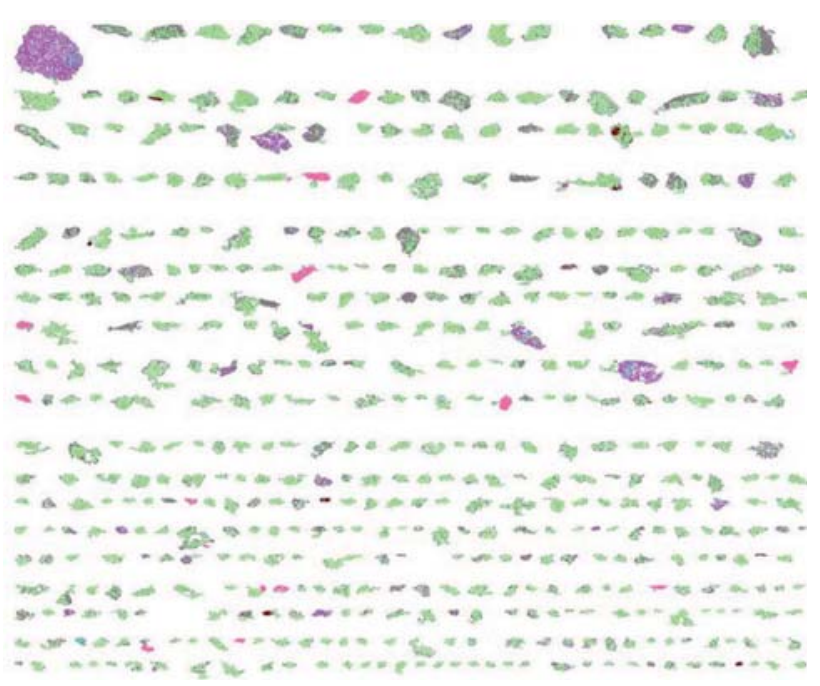

Figure 1-Particle map of iron ore slime

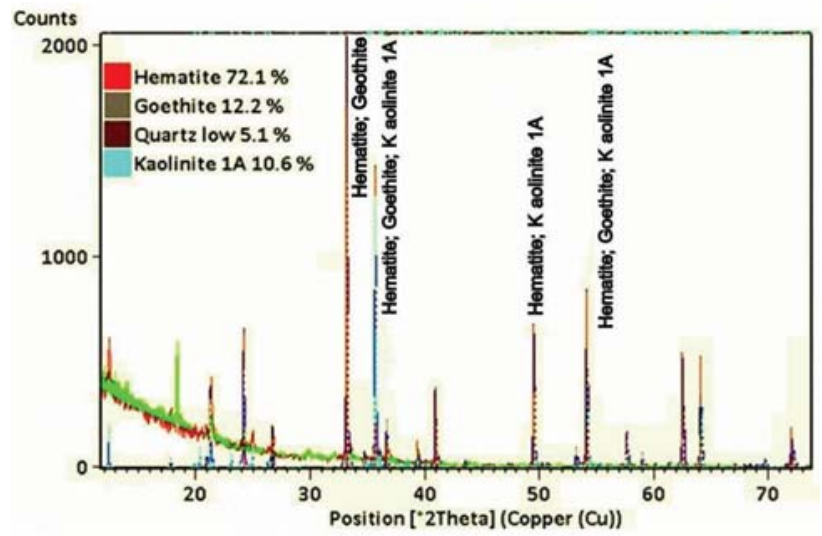

Figure 2-X-ray diffraction pattern of iron ore slimes

\section{$X$-ray diffraction analysis (XRD)}

XRD studies were carried out using a Rigaku X-ray diffractometer (model Ultima IV) with $\mathrm{Cu} \mathrm{K}_{\alpha}$ as the target. The XRD spectrum is given in Figure 2. It can be seen that the major iron-bearing minerals are haematite and goethite, with silicate gangue minerals such as kaolinite and quartz.

\section{Field emission scanning electron microscopy}

A Carl Zeiss model Supra 55 thermal field emission scanning electron microscope (FE-SEM) was used for the study. The results, which are given in Figure 3, indicate that the sample contains variable quantities of gangue minerals such as alumina and silica, along with iron. Plate-like particles are visible in the micrograph, which shows the presence of goethite in the sample.

\section{Flocculation tests}

The standard test procedure described in the literature was adopted for flocculation (Mandre and Panigrahi, 1997). Flocculation tests were carried out in a $1000 \mathrm{ml}$ graduated cylinder. For this purpose a desired amount of $-75 \mu \mathrm{m}$ iron ore slimes was mixed in $950 \mathrm{ml}$ water and the $\mathrm{pH}$ of the slurry was adjusted by adding $\mathrm{NaOH}$ and $\mathrm{HCl}$. The required amount of dispersant was then added to the slurry. The slurry was thoroughly mixed for 2 minutes using a perforated plunger. The requisite amount of flocculant was then added, followed by mixing for 1 minute. After thorough mixing, the slurry was allowed to settle for a specified time and the supernatant (upper $75 \%$ part) was siphoned off. Four-stage washing of the flocs was carried out by adding make-up water to the settled portion from the previous stage. The
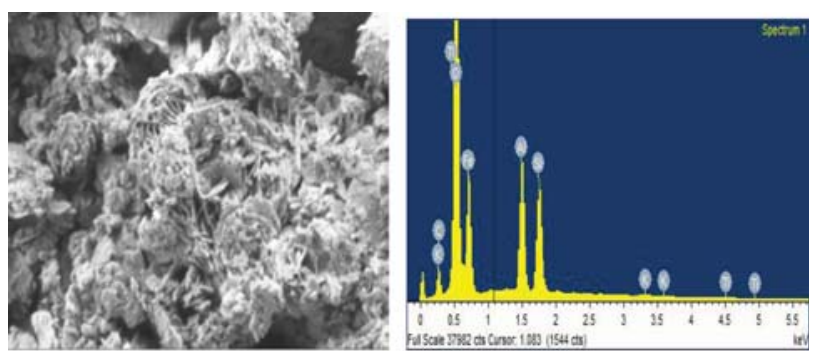

Figure 3-FE-SEM micrograph and EDS pattern of the feed sample 


\section{Recovery of iron from iron ore slimes by selective flocculation}

flocculated and unflocculated masses were collected separately, dried, and subjected to chemical analysis.

\section{Results and discussion}

Prior to the flocculation studies, initial settling studies were carried out to ascertain the settling characteristics and effect of $\mathrm{pH}$ on the 'free' settling rate of the slimes. The results are shown in Figure 4. It may be seen that the settling rate of iron ore slimes decreases with increasing pulp density and increases with increasing $\mathrm{pH}$. The maximum settling rate of $1.1 \mathrm{~cm} / \mathrm{s}$ was obtained at $\mathrm{pH} 12$ using a pulp density of $1 \%$ by weight. This may be attributed to the fact that at higher $\mathrm{pH}$ values all the particles (both iron and gangue minerals) tend to settle. In order to initiate selective flocculation, the

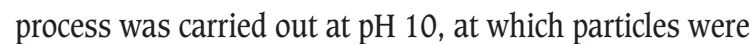
found to be in a transition state. Therefore, all the studies were carried out at $\mathrm{pH} 10$. After completion of the above tests, selective flocculation studies were carried out using different dosages of PAM and guar gum as the flocculants and sodium hexametaphosphate dispersant. Also, studies were carried out using a dispersant dose of $0.5 \mathrm{mg} / \mathrm{g}$.

The results of the flocculation tests with PAM are depicted in Figure 5. It can be seen that the iron grade of the

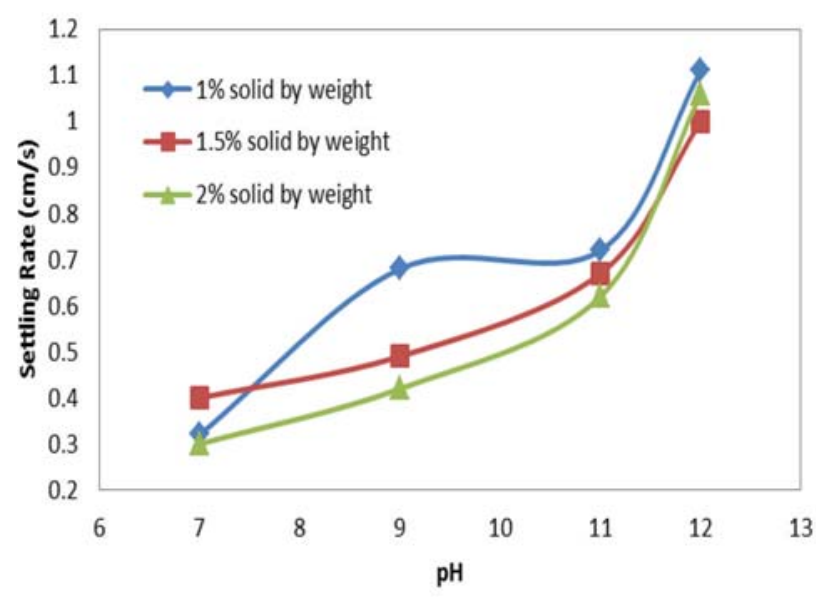

Figure 4-Effect of pH on settling rate at various pulp densities

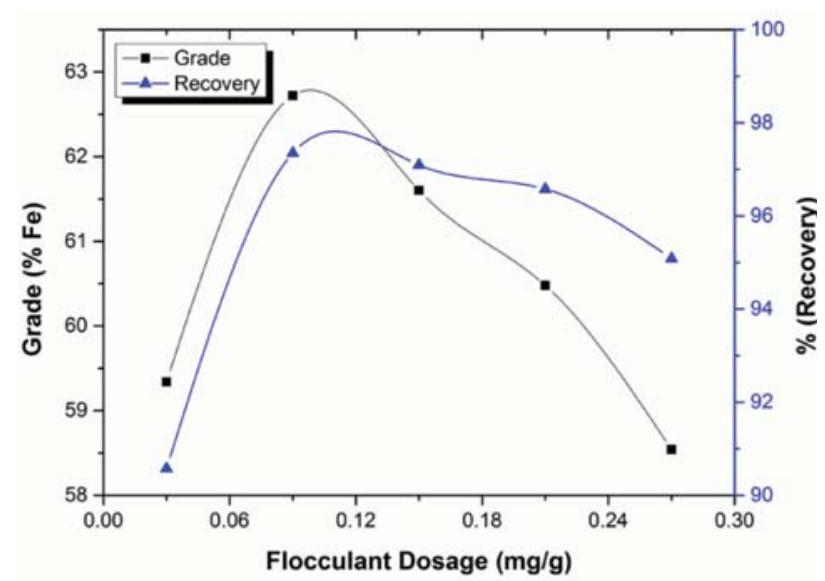

Figure 5-Effect of polyacrylamide flocculant dosage on grade and recovery

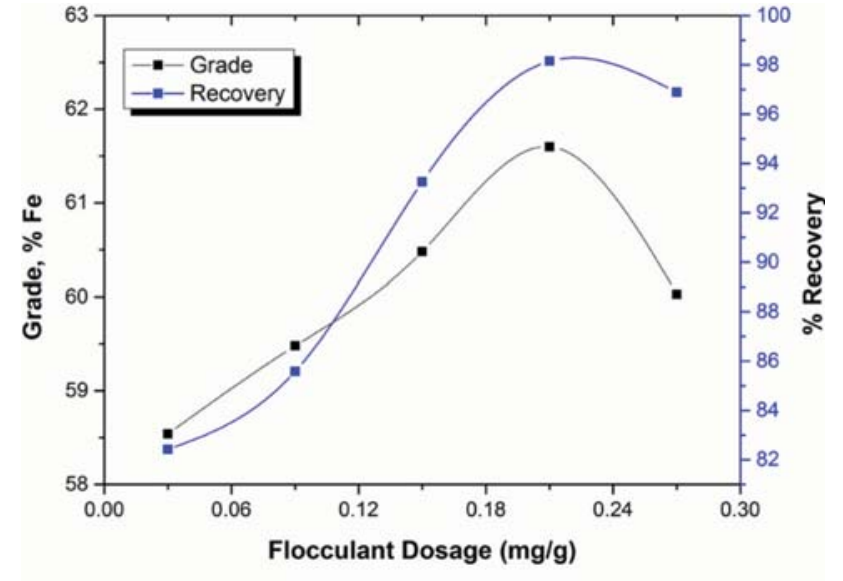

Figure 6-Effect of guar gum flocculant dosage on grade and recovery

flocculated settled mass increases with increasing concentration of PAM flocculant to a maximum value of $62.72 \%$ at a recovery of $97.35 \%$ using $0.09 \mathrm{mg} / \mathrm{g}$ PAM. However, with PAM additions greater than $0.09 \mathrm{mg} / \mathrm{g}$ the iron grade decreased, with increasing recovery, which may be attributed to the haematite particles being covered by excess polymer and thus forming polymer 'bridges' between the haematite and the gange particles .

The effect of guar gum dosage is depicted in Figure 6. The results are similar to those for PAM. A maximum grade of $61.60 \%$ Fe in the flocculated settled mass with a recovery of $98.15 \%$ was obtained using $0.21 \mathrm{mg} / \mathrm{g}$ of guar gum flocculant, which may be attributed to agglomeration and entrapment of gangue particles. It may be noted that the experiments carried out with PAM resulted in a higher iron grade than those with guar gum. The PAM flocculant selectively adsorbs onto the haematite particles up to a dose of $0.09 \mathrm{mg} / \mathrm{g}$ flocculant. With further increases the flocculant tends to adsorb onto the gangue minerals in the slimes and forms polymer bridges with the haematite particles, which then settle together with the gangue minerals. Previous studies (Khangaonkar and Balasubramani, 1993; Ma and Pawlik, 2005; Nasser and James, 2007; Rath, Subramanian, and Laskowski, 1997; Wang, Somasundaran, and Nagaraj, 2005) have shown that the adsorption of these flocculants on the surfaces of the oxide minerals is due mainly to hydrogen

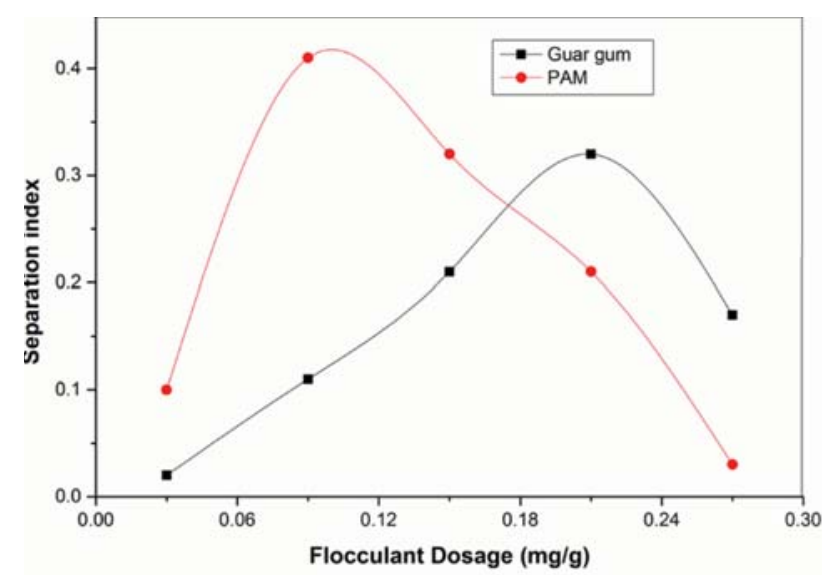

Figure 7-Effect of flocculant dosage on separation index before washing 


\section{Recovery of iron from iron ore slimes by selective flocculation}

\begin{tabular}{|c|c|c|c|c|c|c|}
\hline \multicolumn{7}{|c|}{$\begin{array}{l}\text { Table II } \\
\text { Effect of } \\
\text { separati }\end{array}$} \\
\hline \multirow{2}{*}{$\begin{array}{c}\text { No. of } \\
\text { washing }\end{array}$} & \multicolumn{2}{|c|}{ Grade } & \multicolumn{2}{|c|}{ Recovery } & \multicolumn{2}{|c|}{ Separation Index } \\
\hline & Guar gum ${ }^{\circ}$ & $\mathrm{PAM}^{\prime \prime}$ & Guar Gum & PAM & Guar gum & PAM \\
\hline 1 & 61.92 & 62.96 & 86.33 & 85.62 & 0.31 & 0.38 \\
\hline 2 & 62.34 & 63.42 & 78.78 & 76.01 & 0.31 & 0.37 \\
\hline 3 & 62.87 & 63,84 & 72.76 & 70.59 & 0.32 & 0.37 \\
\hline 4 & 63.2 & 64.6 & 68.04 & 66.33 & 0.32 & 0.39 \\
\hline
\end{tabular}

bonding and chemical interaction. The results indicate that flocculant extension, and thus bridging, is most likely to occur when the flocculant covers only half of the particle surface. Above this level, the likelihood of flocculant extension and bridging decreases due to complete surface coverage of the particles by the flocculants, which may result in slurry stabilization.

All the experiments carried out were reviewed to assess the effectiveness of the flocculation by calculating separation indices. The separation index (SI) can be calculated using Equation [1], suggested by Sresty and Somasundaran (1980). The results of the studies are given in Figure 7.

$\mathrm{SI}=[(\%$ of valuable mineral recovered in the concentrate $)+(\%$ of gangue rejected in the tailings) - 100]/100

Figure 7 shows that the separation indices of the selective flocculation process increased with increasing PAM concentration to a maximum value of 0.41 at a PAM dosage of $0.09 \mathrm{mg} / \mathrm{g}$, whereas for guar gum the maximum value of separation index was 0.32 at a dosage of $0.21 \mathrm{mg} / \mathrm{g}$. However, at dosages of more than $0.09 \mathrm{mg} / \mathrm{g}$ of PAM, and $0.21 \mathrm{mg} / \mathrm{g}$ of guar gum, the SI decreased. This may be attributed to surface heterogeneity of the particles, where the flocculants adsorb on the gangue minerals and co-flocculate with the iron mineral particles, causing a decrease in selectivity. Thus, the flocculants adsorbed on the gangue mineral bridges with iron minerals particles to form flocs, leading to heteroflocculation.

After completion of the above studies, tests were carried out to determine the effect of washing of the flocs on grade, recovery, and separation index. A four-stage cleaning technique was employed, and the results are given in Table II. It can be seen that at a PAM dosage of $0.09 \mathrm{mg} / \mathrm{g}$, after four stages of cleaning the grade increased to $64.60 \%$ with a recovery of $66.33 \%$. Similarly, with $0.21 \mathrm{mg} / \mathrm{g}$ of guar gum the grade increases to $63.20 \%$ after four stages of cleaning with a corresponding recovery of $68.04 \%$. The maximum separation index was 0.39 for PAM and 0.32 for guar gum, which may be attributed to the removal of entrapped gangue minerals from the flocs formed. After four stages of washing, the grade of iron ore slimes was improved by $2.99 \%$ in case of PAM, and by $2.60 \%$ in the case of guar gum.

\section{Conclusions}

> Mineralogical studies indicated that haematite and goethite are the major iron-bearing minerals, and quartz and kaolinite the major gangue minerals

> The studies carried out to determine the effect of 'free settling rate' of iron ore slimes indicated that the settling rate increases with increasing $\mathrm{pH}$, irrespective of the variation in pulp density
> A maximum grade of $64.6 \%$ Fe at a recovery of $66.33 \%$ was obtained with $0.09 \mathrm{mg} / \mathrm{g}$ PAM at $\mathrm{pH} 10$ and 0.5 $\mathrm{kg} / \mathrm{t}$ sodium hexametaphosphate

$>$ A maximum grade of $63.20 \% \mathrm{Fe}$ at a recovery of $68.04 \%$ was obtained with $0.21 \mathrm{mg} / \mathrm{g}$ guar gum at $\mathrm{pH}$ of 10 and a dispersant dose of $0.5 \mathrm{mg} / \mathrm{g}$

> The studies indicated a maximum separation index of 0.39 for PAM, and 0.32 for guar gum, after four stages of washing.

\section{Acknowledgements}

The authors would like to acknowledge Steel Authority of India Ltd. for providing the iron ore slimes for this investigation. Thanks are also due to CRF of Indian School of Mines, Dhanbad and Tata Steel, Jamshedpur.

\section{References}

Batisteli, G.M.B. and Peres, A.E.C. 2008. Residual amine in iron ore flotation. Minerals Engineering, vol. 21, no. 12-14. pp. 873-876.

DAS, B., PraKash, S., DAS, S.K., and RedDy, P.S.R. 2007. Effective beneficiation of low grade iron ore through jigging operation. Journal of Minerals and Materials Characterization and Engineering, vol. 7, no.1. pp. 27-37.

Drzymala, J. and Fuerstenau, D.W. 1981. Selective flocculation of hematite in the hematite-quartz-ferric ions-polyacrylic acid system. Part I. Activation and deactivation of quartz. International Journal of Mineral Processing, vol. 8. pp. 265-277.

Dworzanowski, M. 2012. Maximizing the recovery of fine iron ore using magnetic separation. Journal of the Southern African Institute of Mining and Metallurgy, vol. 112, no. 3. pp. 197-202.

HASElhuhn, H.J., CARLSON, J.J., and KaWATRA, S.K. 2012. Water chemistry analysis of an industrial selective flocculation dispersion hematite ore concentrator plant. International Journal of Mineral Processing, vol. 102-103. pp. 99-106.

Jin, R., Hu, W., and Hou, X. 1987. Mechanism of selective flocculation of hematite from quartz with hydrolysed polyacrylamide. Colloids and Surfaces, vol. 26. pp. 317-331.

KHANGaOnKar, R., Subramani, P., and BaLA, K.J. 1993. Flocculation of hematite fines by anionic polyacrylamide polymers. Minerals Engineering, vol. 6 . pp. $765-774$

MA, M. 2012. The significance of dosing sequence in the flocculation of hematite. Chemical Engineering Science, vol. 73. pp. 51-54.

MA, X. and РАwLIK, M., 2007. Role of background ions in guar gum adsorption on oxide minerals and kaolinite. Journal of Colloid and Interface Science, vol. 313. pp. 440-448.

MANDRE, N.R. and PANIGRAHI, D. 1997. Studies on selective flocculation of complex sulphides using cellulose xanthate. International Journal of Mineral Processing, vol. 50. pp. 177-186.

NASSER, M.S. and JAMES, J.E. 2007. Effect of polyacrylamide polymers on floc size and rheological behaviour of kaolinite suspensions. Colloids and Surfaces A: Physicochemical and Engineering Aspects, vol. 301. pp. 311-322.

Panda, L., BanerjeE, P.K., BisWal, S.K., Venugopal, R., and MandRe, N.R. 2013. Performance evaluation for selectivity of the flocculant on hematite in selective flocculation. International Journal of Minerals, Metallurgy and Materials, vol. 20, no. 12. pp. 1123-1129.

Rath, R.K., Subramanian, S., and LASKowski, J.S. 1997. Adsorption of dextrin and guar gum onto talc. A comparative study. Langmuir, vol. 13. pp. 6260-6266.

RAviSHANKAR, S.A. and Pradip KHosLA, N.K. 1995. Selective flocculation of iron oxide from its synthetic mixtures with clays: a comparison of polyacrylic acid and starch polymers. International Journal of Mineral Processing, vol. 43, no. 3-4. pp. 235-247.

Rocha, L., CANEAdo, R.Z.L., and Peres, A.E.C. 2010. Iron ore flotation. Minerals Engineering, vol. 23, no. 11-13. pp. 842-845.

SRESTY, G.C. and SomasundRAn, P. 1980. Selective flocculation of synthetic mineral mixtures using modified polymers. International Journal of Mineral Processing, vol. 6. pp. 303-320.

WANG, J., SOMASUnDRAn, P., and Nagaraj, D.R. 2005. Adsorption mechanism of guar gum at solid liquid interfaces. Minerals Engineering, vol.18. pp. $77-81$.

WeISSENBoRN, P.K., WARREN, L.J., and DunN, J.G. 1994. Optimisation of selective flocculation of ultrafine iron ore. International Journal of Mineral Processing, vol. 42. pp. 191-213. 